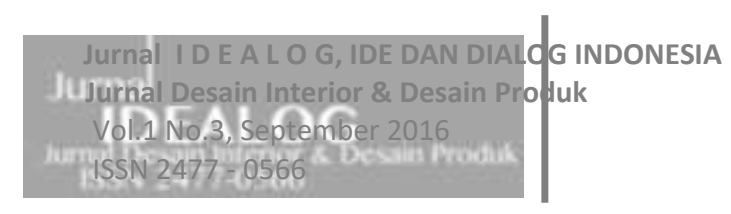

\author{
Arizky Bara Ayuningrum \& Imtihan Hanum \\ Universitas Telkom \\ arrizkybara@hotmail.com \\ imtihan@telkomuniversity.ac.id
}

\title{
KAJIAN PENCAHAYAAN BUATAN SEBAGAI PROSES RELAKSASI PADA RUANG REFLEXOLOGY DI EVERYDAY BALINESE SPA \& REFLEXOLOGY
}

\begin{abstract}
Abstrak: Tujuan utama pencahayaan pada fasilitas Health Care adalah untuk meningkatkan fungsi health care itu sendiri, karena pencahayaan merupakan salah satu unsur penting dalam sebuah gedung atau bangunan. Faktor yang menentukan berhasil tidaknya perencanaan pencahayaan di dalam ruangan tergantung dari kondisi bangunan itu sendiri. Penerangan yang baik di tempat fasilitas health care adalah penerangan yang tidak menyebabkan terjadinya penurunan relaksasi tubuh saat melakukan proses yang relaxive. Oleh karena fungsi fasilitas health care adalah memberikan fasilitas yang relaxive yang dapat membantu dalam penanggulangan stres. Dengan mengkaji studi kasus bangunan pusat perawatan tubuh dan kecantikan di Everyday Balinese Spa \& Reflexology yang berada di Jl. Naripan No. 38 Bandung dengan fokus kajian pada ruang Relexology, diketahui bahwa sebuah fasilitas Health care membutuhkan karakteristik ruang dengan desain interior yang dapat menunjang perawatan kesehatan, baik fisik maupun mental, sehingga suatu ruang juga dapat menjadi media terapi kesehatan melalui treatment pada elemen-elemen interior, salah satunya yaitu sistem pencahayaanya. Dengan demikian, penelitian ini penting untuk dilakukan karena dapat diketahui apakah dalam kajian ini pencahayaan buatan pada pusat perawatan tubuh dan kecantikan di Everyday Balinese Spa \& Reflexology sudah sesuai dengan fungsi pencahayaannya yang dapat memberikan suasana relaksatif atau belum. Kata kunci: pencahayaan buatan, interior, releksasi, Pusat Perawatan Tubuh dan Kecantikan Everyday Balinese Spa \& Reflexology.
\end{abstract}

\begin{abstract}
The main purpose of lighting in a Health Care facility is to improve the functioning of health care itself, because the lighting is one important element in a building or buildings. The factors that determine the success or failure of planning the lighting in the room depending on the condition of the building itself. Good lighting in a health care facility is lighting that does not cause a decrease in body relaxation while doing relaxation process. Because the function of health care facilities is to provide facilities to relaxation that can assist in the response to stress. By reviewing case studies center building body and beauty treatments in Everyday Balinese Spa\&Reflexology is located on Jl. Naripan No. 38 Bandung to study focuses on space Reflexology known that a facility Health care requires the characteristics of a living room with interior design that can support health care physically and mentally, so that a space can also be a medium for health therapy through treatment on interior elements, one of which the lighting system. So this research is important to do because it can be known whether in the study of artificial lighting in the center of body and beauty treatments in Everyday Balinese Spa\&Reflexology is in conformity with the lighting function to provide the atmosphere relexation or not.
\end{abstract}

Keywords: Artificial Lighting, Interior, relaxation, health and beauty care Center Everyday Balinese Spa\&Reflexology.

\section{PENDAHULUAN}




\subsection{Latar Belakang}

Dengan meningkatnya kebutuhan hidup masyarakat, bekerja menjadi suatu kewajiban bagi hampir setiap golongan masyarakat, baik wanita maupun pria, untuk memenuhi kebutuhan hidupnya. Dengan bekerja secara rutin setiap hari, suasana di tempat kerja pun tidak selalu menyenangkan, kadang kala muncul permasalahan di lingkungan kerja, bosan dengan rutinitas yang monoton, bahkan permasalahan di lingkungan keluarga. Hal ini jika dibiarkan berlarut-larut, lama kelamaan akan memengaruhi psikologis manusia, manjadi stres. Berelaksasi atau sekedar mengendurkan syaraf-syaraf, dipercaya dapat menyeimbangkan kembali fisik dan mental. Sejalan dengan perkembangan relaksasi di Indonesia, relaksasi dengan cara alami semakin diminati. Salah satunya adalah reflexology, yang sekarang sudah semakin banyak berkembang di Indonesia, bahkan reflexology, sebagai kegiatan utama dari perawan tubuh, saat ini tidak lagi menjadi kebutuhan untuk merelaksasi dan mengembalikan kebugaran tubuh, tetapi sudah menjadi gaya hidup masyarakat modern, salah satunya adalah di Kota Bandung. Namun yang menjadi permasalahan, walaupun ada tempat sejenis, belum ada tempat yang khusus mempraktikkan ilmu desain spesifik dengan tujuan relaksasi penggunanya. Dari hal tersebut dapat dilihat bahwa efek relaksasi yang diperuntukkan bagi para customer dititikberatkan pada servis dan fasilitas yang disediakan oleh tempat tersebut, dan pengaruh ruang terhadap pengguna pada desain interior yang relaxive pun tidak dirasakan. Terdapat banyak unsur desain pada interior yang dapat dimanfaatkan dalam proses penciptaan ketenangan dan relaksasi selain dari servis fasilitas relaksasi itu sendiri, salah satunya adalah dari aspek pencahayaan buatan di dalam interior pusat perawatan tubuh dan kecantikan. Di sini penulis melakukan observasi dengan mengambil studi kasus di tempat perawatan tubuh dan kecantikan yang berada di Bandung, yaitu Everyday Balinese Spa \& Reflexology. Fasilitas perawatan tubuh dan kecantikan membutuhkan karakteristik ruang dengan desain interior yang dapat menunjang perawatan kesehatan, baik fisik maupun mental, sehingga suatu ruang juga dapat menjadi media terapi kesehatan melalui treatment pada elemen-elemen interior. Kenyamanan ruangan juga menjadi hal penting bagi penghuninya. Unsur kenyamanan meliputi kenyamanan temis, kelembaban akustik, penghawaan termasuk kualitas cahaya di dalam ruangan yang dipengaruhi oleh semua elemen yang berada dalam ruangan itu sendiri, termasuk perilaku pengguna ruangan dan sistem cahaya yang dihasilkan dari penerangan tersebut. Manusia, ruang-bangunan, dan lingkungan menjadi bagian kesatuan. Hasil cahaya yang dihasilkan dari penerangan yang disesuaikan antara aktivitas manusia, wujud dan penggunaan ruang, serta sumber daya akan menghasilkan keseimbangan yang baik antara manusia, ruang-bangunan, dan lingkungan sekitar, sehingga menjadikan proses treatment spa menjadi berjalan lancar. Tujuan penulisan ini adalah untuk mengetahui tingkat kenyamanan fungsional dan apakah pencahayaan buatan dapat berpengaruh terhadap proses relaksasi pada area reflexology di Everyday Baliness Spa sehingga manfaat yang dapat dipetik dari penelitian ini adalah untuk mengetahui lebih jauh aspek-aspek yang harus diperhatikan dalam merancang pencahayaan pada ruang reflexology di sebuah tempat spa.

\subsection{Kondisi Everyday Balinese Spa and Reflexology}

Kondisi bangunan Everyday Balinese Spa and Reflexology yang berlokasi di Jl. Naripan No. 38, Kb. Pisang, Sumur Bandung, Kota Bandung, Jawa Barat 40112, sudah dibuat dengan memenuhi standar fasilitas Health Care. 


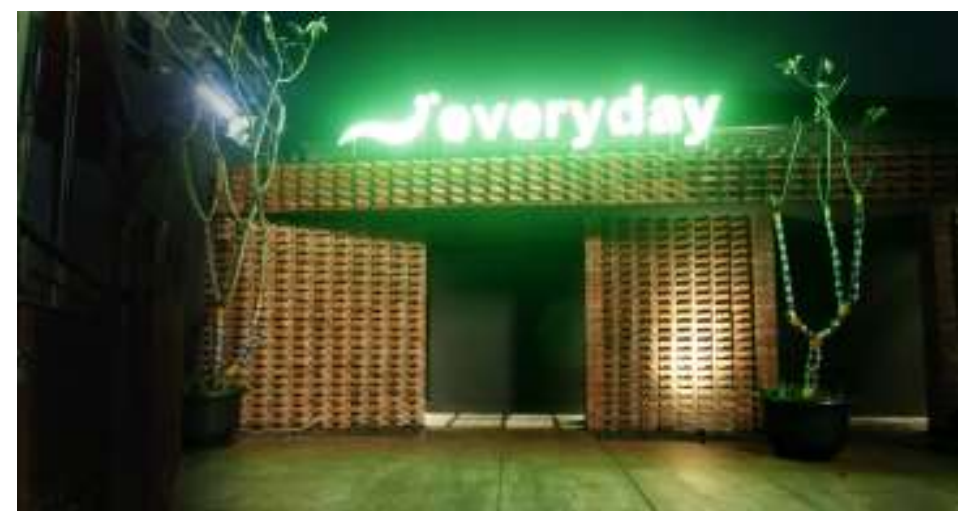

Gambar 1.1 Tampak fasad bangunan

Sumber: http://everydayspa.co.id/\#gallery

Di Everyday Balinese Spa \& Reflexology terdapatnya berbagai fasilitas pendukung kegiatan yang dibutuhkan untuk setiap aktivitas pelanggan dengan berbagai macam varian treatment yang di sediakan.

Tabel 1. Varian treatment

Disediakan Everyday Balinese Spa \& Reflexology di Jl. Naripan No 38 Bandung

\begin{tabular}{|c|l|c|l|}
\hline No & \multicolumn{1}{|c|}{ Varian Treatment No } & \multicolumn{1}{|c|}{ Varian Treatment } \\
\hline 1 & $\begin{array}{l}\text { Amazing Balinese } \\
\text { (Body Relax + Herbal Punch + Chocolate } \\
\text { Mask + Face Massage) }\end{array}$ & 8 & Firm Massage 60/90 minute \\
\hline 2 & $\begin{array}{l}\text { Heritage Dreamland } \\
\text { Body Complete + Body Scrub + Face } \\
\text { Massage) }\end{array}$ & 9 & Oil Free 60/90 minute \\
\hline 3 & $\begin{array}{l}\text { Art of Ubud } \\
\text { Body Relax + Body Scrub Face } \\
\text { Massage) }\end{array}$ & 10 & Royal Reflexology \\
\hline 4 & $\begin{array}{l}\text { Exotic Bali } \\
\text { Body Relax + Body Scrub Ear Candle) }\end{array}$ & 11 & $\begin{array}{l}\text { Quick Fresh (Foot/Back/Head } \\
\text { Shoulder) }\end{array}$ \\
\hline 5 & $\begin{array}{l}\text { Body Relax 60/90/120 minute } \\
6\end{array}$ & 12 & Face Massage \\
\hline 7 & Body Complete 90/120 minute & 13 & Ear Candle \\
\hline
\end{tabular}

\section{LANDASAN TEORI}

Teori yang digunakan untuk menganalisis hasil penelitian ini adalah teori yang berhubungan dengan judul penelitian, yaitu mengenai peran pencahayaan buatan terhadap proses relaksasi pada ruang reflexology di Everyday Baliness Spa and Reflexology. Berdasarkan pembahasan 
yang dipilih dan dikaji, terdapat beberapa dasar literatur yang mendukung, di antaranya adalah sebagai berikut:

\subsection{Teori Penerapan Pencahayaan}

Pencahayaan berasal dari kata cahaya yang merupakan gelombang magnet elektro atau radiasi. Pencahayaan merupakan salah satu faktor untuk mendapatkan keadaan lingkungan yang aman dan nyaman dan berkaitan erat dengan produktivitas manusia. Pencahayaan yang baik memungkinkan orang dapat melihat objek-objek yang dikerjakannya secara jelas dan cepat.

Menurut Norbert Lechner (2007:282) dalam bukunya Heating, Cooling, and lighting edisi Sustainable Method for Architect, ada beberapa prinsip dan aturan tentang mendesain penerangan umum, yaitu:

1. Pertama, menentukan program pencahayaan yang diinginkan dengan sepenuhnya, untuk menentukan pencahayaan apa yang dibutuhkan pada setiap ruang.

2. Menerangi hal-hal yang kita inginkan atau butuhkan untuk melihat.

3. Pencahayaan yang berkualitas sebagian besar merupakan suatu masalah geometri. Sumber cahaya utama tidak boleh di depan penonton. Cahaya yang berlebih (silau) juga dapat dicegah dengan pencahayaan tidak langsung.

4. Pada beberapa situasi, yang terbaik adalah cahaya yang terdiri dari kombinasi cahaya yang langsung dan menyebar sehingga akan menghasilkan bayangan yang lembut dan shading agar kita dapat sepenuhnya memahami kualitas dunia tiga dimensi kita.

5. Kegelapan sama pentingnya dengan cahaya, hindari rasio kecerahan yang sangat besar yang memaksa mata untuk beradaptasi kembali terus menerus.

6. Sebuah objek atau daerah dapat diterangi dengan baik, dengan keadaan yang tidak begitu terang maupun gelap.

7. Gunakan pencahayaan alami seefektif mungkin.

8. Fleksibilitas dan kualitas lebih penting daripada kuantitas cahaya, dan tujuantujuan ini paling mudah dicapai dengan tugas/pencahayaan ambien. Lampu yang fleksibel memberikan banyak manfaat: mereka yang hemat energi, berkualitas tinggi, mereka bekerja dengan baik dengan komputer, mereka merespon dengan baik untuk kebutuhan pengguna individu, dan mereka memberikan kepuasan pengguna karena mereka memungkinkan penghuni untuk mengontrol pencahayaan ENVI sendiri.

\subsection{Teori Pencahayaan Buatan Dapat Memengaruhi Proses Relaksasi}

Pencahayaan dalam sebuah interior memegang peranan yang sangat penting untuk mencapai titik relaxive para penggunanya. Belakangan ini, para ilmuwan, desainer, dan psikolog memercayai bahwa cahaya memiliki peranan yang amat penting pada mood seorang manusia terhadap sikap sosial seseorang. Menurut artikel dalam sebuah website oleh George C. Brainard (2011: http://www.controlledenvironments.org/Light1994Conf/index.htm ) "This part of the brain is considered to be a fundamental part of the "biological clock", or circadian system, which regulates the body's physiological rhythms. The circadian system is thought to be responsible for controlling daily rhythms such as sleep and wakefulness, body temperature, hormonal secretion and other physiological parameters including cognitive function. It is now clear that light is the primary stimulus for regulating the circadian system, 


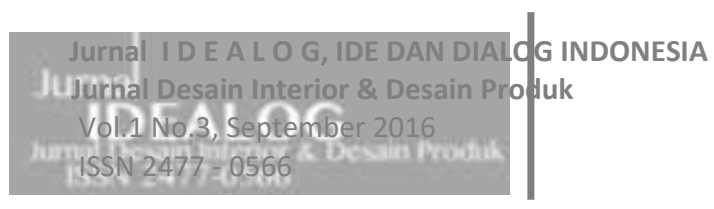

although other external stimuli such as sound, temperature and social cues may also influence the body's timing functions (Aschoff, 1981a; Binkley, 1990)". Dan Menurut artikel dalam sebuah website

(https://kimstevewri101.wordpress.com/literature-review/effects-of-interior-structure-andlights-on-human-mood-changes-and-social-behavior/) "lighting plays an important role on relaxation and emotions. The results of the study reveals that interior designs of lightings and decorations influence communications and relationships."

Dengan mengetahui sejak awal akan kebutuhan ruang yang ingin dituju, yang pada kasus ini yaitu relaksasi, perlu untuk menentukan beberapa teknik dan jenis tersebut sehingga dapat memenuhi kriteria ruang dan individu yang menempatinya. Lampu memberikan kesan psikologis-visual, contohnya:

Efek dari cahaya dapat ditinjau dari tiga aspek, yaitu:

Tabel 2. Efek dari cahaya.

\begin{tabular}{|c|c|c|}
\hline Aspek Visual & Aspek Emosional (psikis) & Aspek Biologis \\
\hline $\begin{array}{l}\text { Yaitu yang berhubungan } \\
\text { dengan tampilan warna } \\
\text { (color appearance) akan } \\
\text { memberikan terhadap } \\
\text { signifikan sebuah } \\
\text { pengguna dari tara } \\
\text { bangunan. Kualitas dari } \\
\text { warna yang ditampikan } \\
\text { sebaiknya bertujuan untuk } \\
\text { membantu menenangkan } \\
\text { pasien dalam proses } \\
\text { perawatan (Pangesu dan Mira, } \\
\text { 2009:81). }\end{array}$ & $\begin{array}{l}\text { Warna-warna hangat dapat } \\
\text { membangkitan semangat dan } \\
\text { dipilih untuk menciptakan suasana } \\
\text { hangat. Namun warna-warna } \\
\text { tersebut juga memiliki efek } \\
\text { negatif, warna cahaya merah dapat } \\
\text { melambangkan panas dan bahaya, } \\
\text { warna cahaya jingga akan terasa } \\
\text { tidak nyaman bagi mata dan } \\
\text { menimbulkan efek yang } \\
\text { membingungkan, sedangkan } \\
\text { cahaya 'dingin', cenderung } \\
\text { memberi pengaruh positif yang } \\
\text { menyejukan/mendinginkan.Seperti } \\
\text { warna hijau memberikan kesan } \\
\text { segar, biru menciptakan suasana } \\
\text { dingin, sejuk, menyegarkan. } \\
\text { Warna yang dihasilkan oleh } \\
\text { cahaya lampu akan mempengaruhi } \\
\text { nuansa suasana dan kesan yang } \\
\text { tercipta pada interior (Pangestu dan } \\
\text { Mira, 2009:81). }\end{array}$ & $\begin{array}{l}\text { Pada tingkat penerangan } \\
\text { tertentu yang berhubungan } \\
\text { dengan temperatur warna, } \\
\text { cahaya akan menstimulasi } \\
\text { hormon cortisol melatonin. } \\
\text { Hormon melatonin akan } \\
\text { meningkat di dalam tubuh } \\
\text { pada saat minimnya } \\
\text { cahaya yang didapat oleh } \\
\text { tubuh manusia sehingga } \\
\text { akan menyebabkan kantuk. } \\
\text { Sedangkan hormon } \\
\text { cortisol pada saat kuat } \\
\text { akan menstimulasi } \\
\text { manusia untuk meanjadi } \\
\text { energik dan bersemangat } \\
\text { (Pangestu dan Mira, 2009:81). }\end{array}$ \\
\hline
\end{tabular}

Menurut Dewi Pangestu dan Mira (2009:81), sistem pencahayaan buatan selalu ditinjau dari tiga aspek, yaitu:

1. Aspek Kuantitas yang bersifat objektif dan terukur

Dapat dinyatakan dalam suatu jumlah/besaran tertentu, seperti jumlah titik cahaya/armatur, umur/jam nyala lampu, kuat penerangan (LUX), tegangan (volt), Daya (watt), kontras dan lain-lain. 
2. Aspek Kuantitas yang berhubungan dengan aspek kualitas

Bersifat terukur namun dapat menimbulkan kesan yang bersifat subjektif, seperti renderasi warna (CRI/Ra), temperatur warna (K), dll. Sumber cahaya dengan CRI 100 berarti lampu tersebut memiliki spektrum warna cahaya selengkap sinar matahari, sehingga tampilan warna objek yang disinari akan seindah warna aslinya. Lampu dengan color temperatur rendah (2000-3000k) termasuk dalam kategori warm light, yang menghasilkan cahaya dengan spektrum merah, orange, dan kuning. Lampu dengan color temperatur tinggi (>4000k) termasuk dalam kategori cool light, yang menghasilkan cahaya kebiruan, sedangkan lampu dengan temperatur warna 4000k akan menhasilkan cahaya yang benar-benar putih.

3. Aspek Kualitas yang bersifat subjektif emosional

Seperti silau, tampilan warna/color apprearance, color rendering capability, color space, sehingga timbul perasaan dan kesan terhadap suasana yang terbentuk.

Kemudian terdapat sistem pencahayaan ditinjau dari aspek desain:

1. Bukaan Cahaya

Pencahayaan pada ruang dalam bangunan umumnya diperoleh dari atas (lubang atap) atau dari samping (lubang/jendela). Dalam praktiknya, pelubangan cahaya dari atap sangat bervariasi tergantung dari fungsi bangunan dan bentuk bangunan yang ada [5].

2. Orientasi Bukaan Cahaya

Bentuk bangunan yang dianjurkan memanjang arah utara-selatan dengan bidang timur dan barat sekecil mungkin, untuk mengurangi panas matahari ke dalam bangunan.

3. Dimensi Ruang Meliputi Luas, Tinggi, dan Kedalaman Ruang

Suatu ruangan dengan dimensi yang luas harus memiliki bukaan cahaya yang cukup besar agar pencahayaan alami dapat diterima secara optimal. Kedalaman ruang juga sangat berpengaruh pada efek pencahayaan dalam ruang. Semakin jauh suatu ruangan terhadap bukaan jendela, maka semakin kurang penerangan yang diterima.

4. Material Interior Ruang dan Furnitur Meliputi Warna dan Tekstur

a. Warna

Warna adalah energi radiasi yang melahirkan unsur estetika atau unsur visual yang memiliki dua unsur jenis, yaitu warna gelap dan terang yang dipengaruhi oleh dua jenis cahaya.

b. Tekstur Interior Ruang

Tekstur adalah pola struktur tiga dimensi permukaan. Tekstur memiliki dua jenis yaitu licin dan kasar. Tekstur yang licin dapat merefleksikan kembali sinar yang jatuh pada permukaan bidang, sedangkan tekstur kasar, cenderung menyerap sinar dan sebagian kecilnya dipantulkan.

Selanjutnya pencahayaan pelengkap interior yang dapat membantu proses relaksasi ialah warna dan dinamisme dari cahaya yang dikeluarkan oleh sumber penerangan tersebut. Seperti yang diterangkan dalam artikel The Influence of Lighting Color and Dynamics on Atmosphere Perception and Relaxation oleh S.H. Wan, J. Ham, D. Lakens, J. Weda, dan R. Cuppen2 (2009: http://www.experiencinglight.nl/ ) di dalam beberapa penelitian, mereka mengemukakan bahwa "Light is essential for human beings. Not only does light allow us to see, it affects our mood, health, and productivity, while shaping deeply the way we experience 


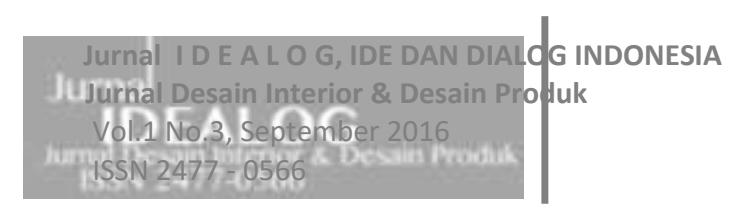

our surroundings. Because light is ubiquitously present in our environment, it has great potential to influence the way we feel, think, and act, and therefore deserves attention in research across disciplines." Menurut artikel tersebut, warna dari cahaya yang memiliki efek relaxive ialah warna dengan tone hangat. Selain dari artikel tersebut banyak sekali komentar dari para ahli yang menyebutkan bahwa tone hangat memiliki efek yang serupa, seperti kutipan dari Flynn dalam buku Interior Lighting For Designer oleh Gary Gordon (2003:46) yang menyatakan bahwa Flynn menjabarkan kategori impresi secara visual pencahayaan dengan tone hangat dan dingin sebagai berikut: warna dingin $(4100 \mathrm{~K})$ menstimulasi impresi kejelasan dalam ruang, sedangkan warna hangat (3000K) menunjukkan impresi kenyamanan, terutama pada saat perasaan rileks sangat dibutuhkan. Jadi, warna yang hangat sangatah membantu seseorang di dalam ruang untuk mencapai ketenangan dan releksasi.

\section{METODE PENELITIAN}

Dalam penelitian ini, metode yang digunakan adalah deskriptif analitis. Menurut Moh. Nazir (1999:63), metode deskriptif analitis adalah suatu metode dalam meneliti status sekelompok manusia, suatu objek, suatu set kondisi, suatu sistem pemikiran ataupun suatu kelas peristiwa pada masa sekarang. Penelitian ini bertujuan mendeskripsikan data yang diperoleh, baik dari berbagai rujukan pustaka maupun dari lapangan, kemudian dianalisis hingga pada akhirnya ditarik kesimpulan berdasarkan hasil analisis yang telah dilakukan.

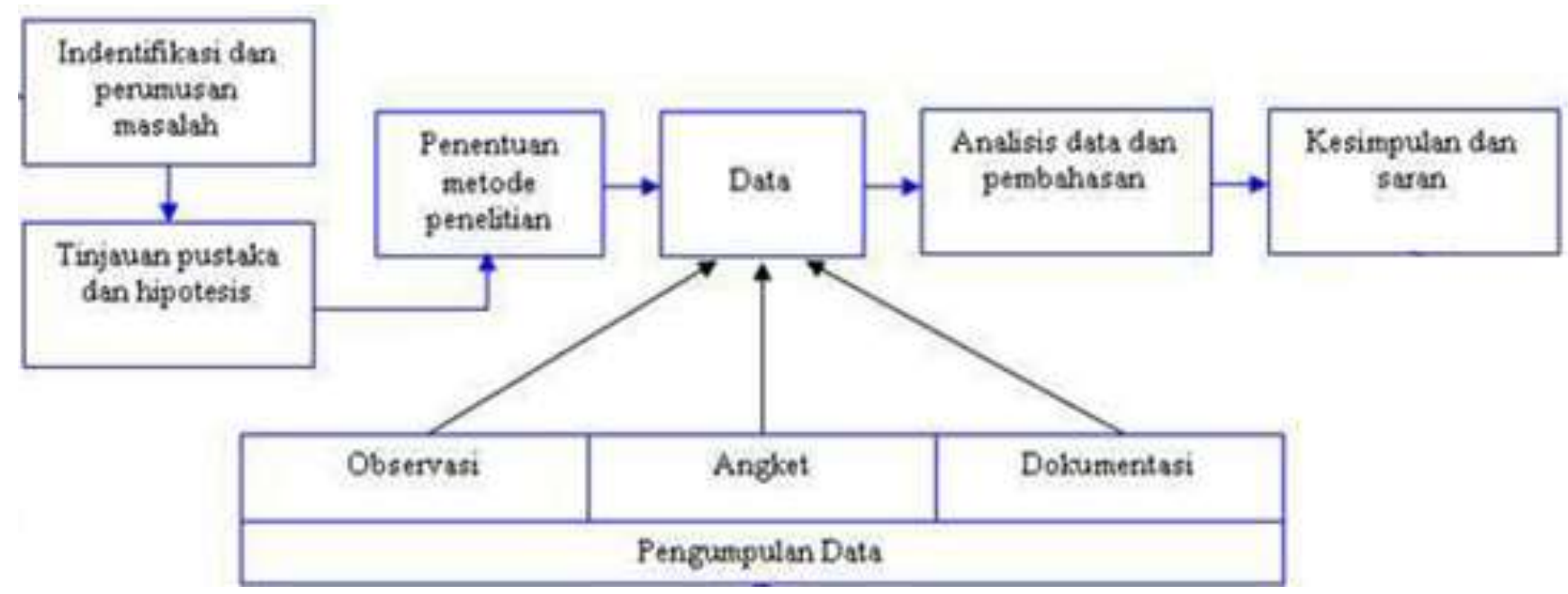

Diagram 1 Alur Penelitian Deskriptif Analitis

Disini penulis melakukan observasi dengan mengambil studi kasus di Everyday Balinese Spa \& Reflexology. Penelitian ini dilakukan dengan membatasi ruang lingkup permasalahan, batasan ruang lingkup yang dipilih yaitu pada ruang reflexology di Everyday Balinese Spa \& Reflexology yang berlokasi di Jl. Naripan No. 38, Kb. Pisang, Sumur Bandung, Kota Bandung, Jawa Barat 40112.

\section{ANALISIS}


Ruang yang dianalisis adalah ruang reflexology. Penelitian yang dilakukan pada area ini adalah untuk mengetahui apakah pencahayaan buatan berpengaruh dalam proses relaksasi pengguna di Pusat Perawatan Tubuh dan Kecantikan Everyday Balinese Spa dan Reflexiology.

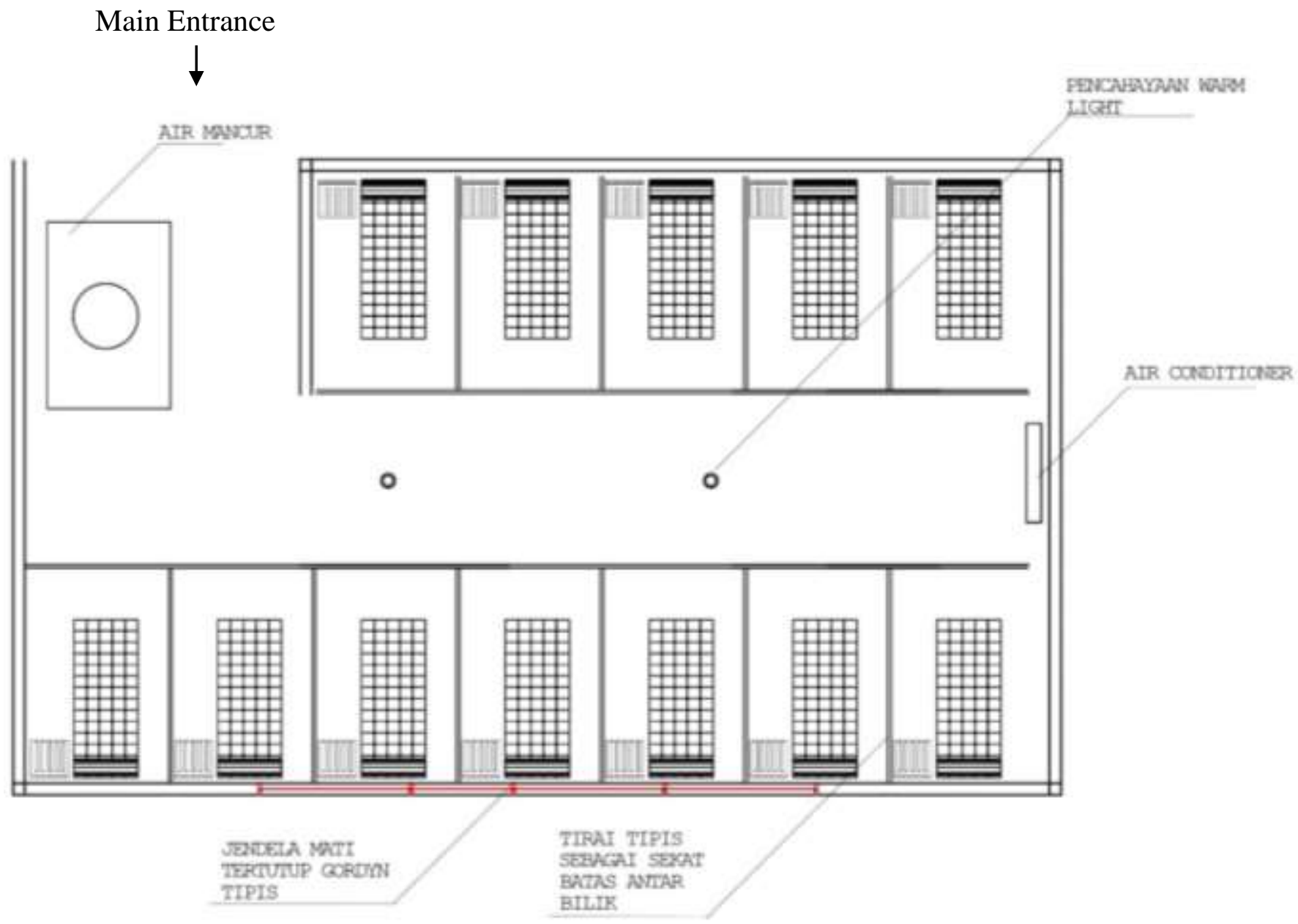

Gambar 4.1 Denah ruang Reflexiology di Everyday Balinese Spa \& Reflexology Jl. Naripan No 38, Bandung

Sumber: Data Pribadi (2015)

Pada denah dapat terlihat bahwa penerangan hanya mengandalkan dua lampu fluorescent 5060 watt. Temperatur warna 3000k, CRI 80+. Luminair: downlight yang tersembunyi di plafon dengan dilapisi trim lensa di lorong ruangan, sehingga fungsi pencahayaan di sana hanya difungsikan sebagai media bantu treatment untuk mendapatkan proses relaks dengan pencahayaan yang redup bila berada dalam ruang yang dilapisi tirai. 

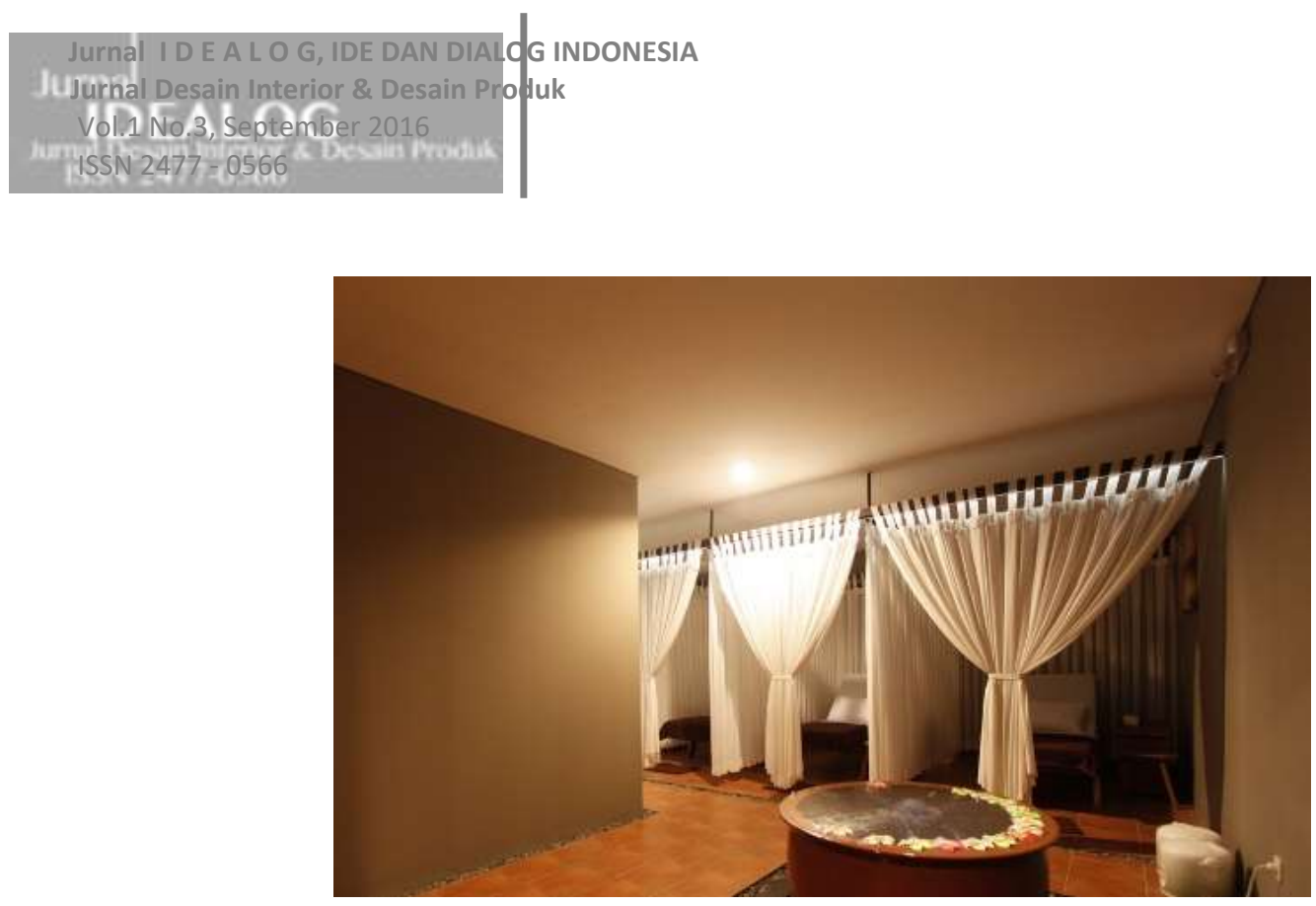

Gambar 4.2. Kondisi dari pintu masuk ruangan

Sumber: Data Pribadi (2015)

Untuk jenis pencahayaan buatan dengan hasil akhir yang berkesan relaksatif, sumber cahaya ditempatkan secara non-uniform untuk menghilangkan kesan formal pada ruang, jenis pencahayaan juga menggunakan tipe indirect untuk menghindari terlihatnya sumber cahaya yang dapat meningkatkan tensi pada visual pengguna.

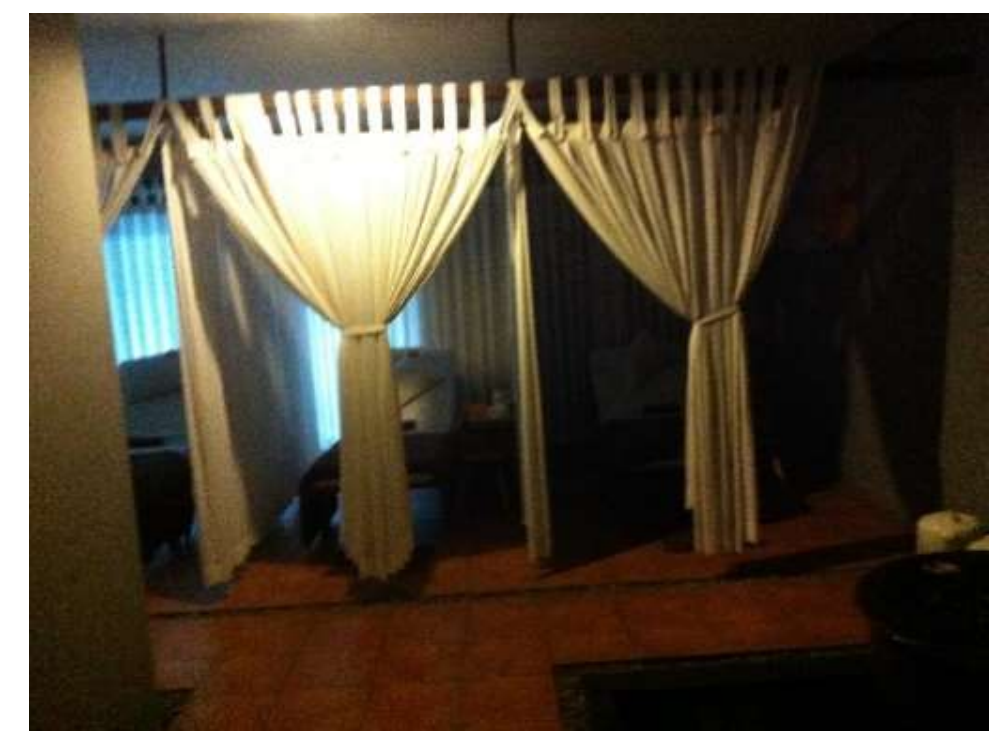

Gambar 4.3. Kondisi dari pintu masuk ruangan

Sumber: Data Pribadi (2015)

Faktor kualitas cahaya lebih penting dibandingkan faktor kuantitas yang hanya diperlukan untuk area-area fungsional. Kualitas pencahayaan sangat berpengaruh terhadap suasana yang dibutuhkan oleh pasien, terutama yang membutuhkan ketenangan jiwa sehingga merasa aman dan nyaman selama dalam perawatan, sehingga tercipta suasana yang dapat membangkitkan emosi, membangun atmosfer, dan menciptakan karakter dari fungsi ruang. 


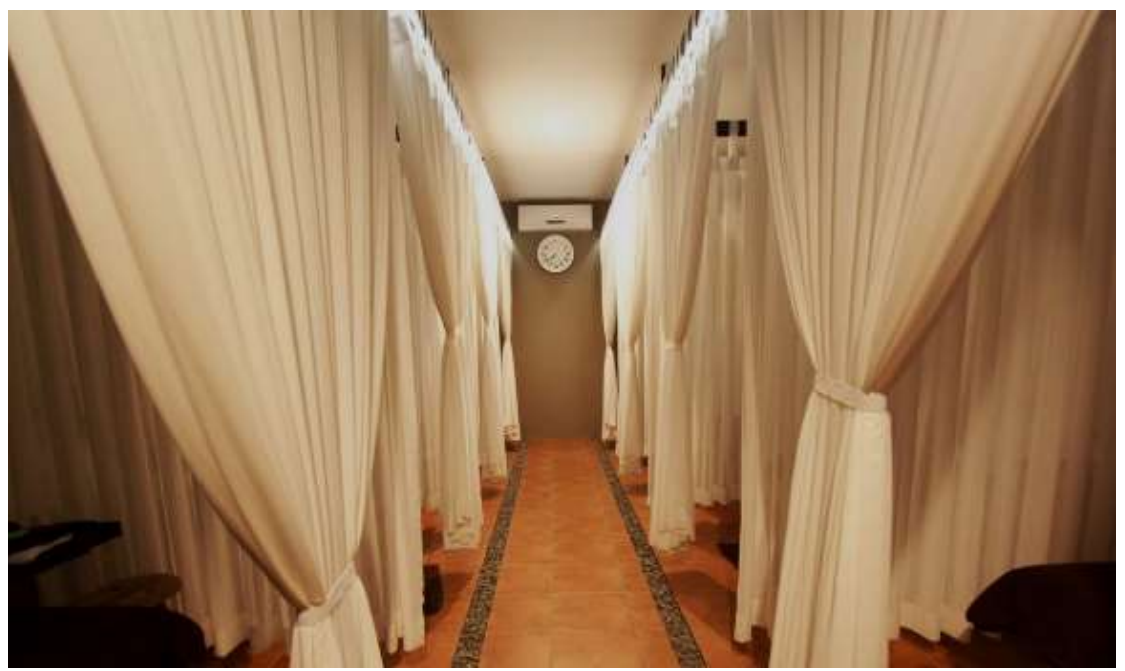

Gambar 4.4. Kondisi lorong ruang reflexology

Sumber: Data Pribadi (2015)

Semua warna cahaya konsisten putih bernuansa kekuningan dengan temperatur warna sebesar 3000k, setara dengan warna putih dari bohlam halogen, dipilih pada bagian-bagian tertentu sebagai aksen visual dan juga agar mata dapat 'beristirahat'. Kuat pencahayaan ditingkatkan menjadi 3-5 kali standar 60-100 lux, sehingga kontras dan berefek dramatis.

\begin{tabular}{|c|c|c|c|c|}
\hline No & $\begin{array}{c}\text { Fungsi ruangan terkait } \\
\text { pencahayaan }\end{array}$ & Jenis Pencahayaan & $\begin{array}{l}\text { Efek yang } \\
\text { dihasilkan }\end{array}$ & Keterangan \\
\hline 1 & 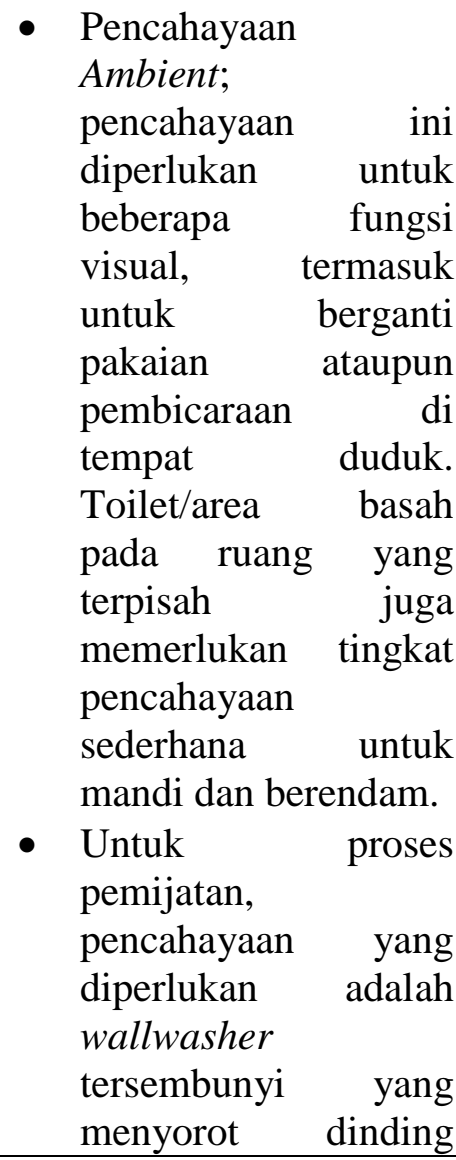 & 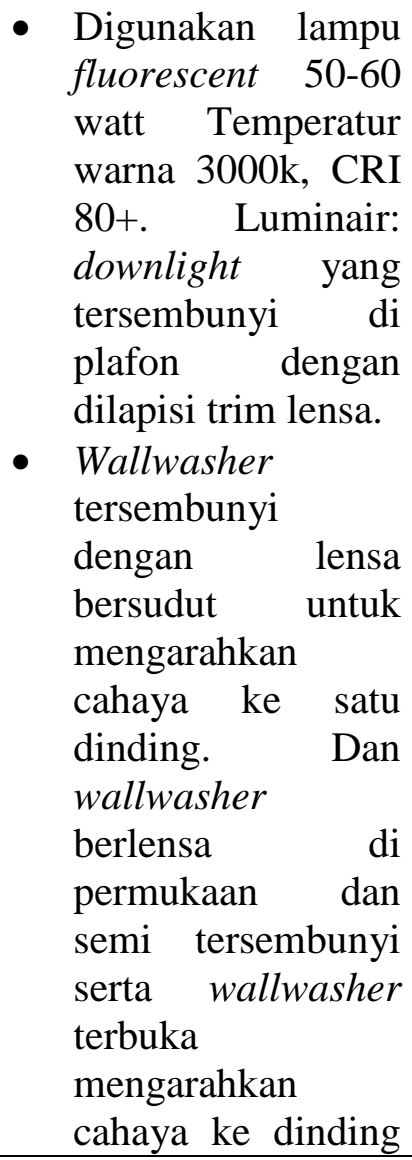 & $\begin{array}{l}\text { Cahaya } \\
\text { redup ini } \\
\text { memberikan } \\
\text { kesan rileks, } \\
\text { tenang dan } \\
\text { romantis, } \\
\text { sehingga } \\
\text { sangat } \\
\text { cocok untuk } \\
\text { digunakan } \\
\text { pada ruang } \\
\text { interior } \\
\text { untuk } \\
\text { relaksasi }\end{array}$ & $\begin{array}{l}\text { Ruang } \\
\text { Reflexology }\end{array}$ \\
\hline
\end{tabular}




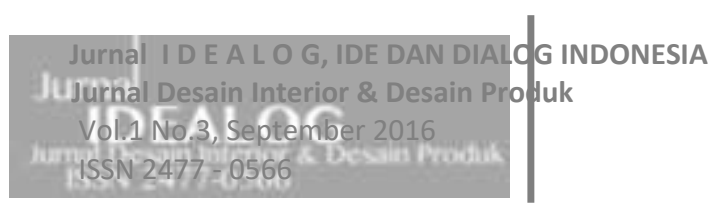

\begin{tabular}{|c|c|c|c|c|}
\hline No & $\begin{array}{c}\text { Fungsi ruangan terkait } \\
\text { pencahayaan }\end{array}$ & Jenis Pencahayaan & $\begin{array}{l}\text { Efek yang } \\
\text { dihasilkan }\end{array}$ & Keterangan \\
\hline & $\begin{array}{l}\text { sehingga memberikan } \\
\text { cahaya tambahan, } \\
\text { bukan sebagai } \\
\text { pencahayaan } \\
\text { dekoratif, tetapi lebih } \\
\text { bersifat fungsional } \\
\text { dan tidak terlihat } \\
\text { (Pangesu dan Mira, } \\
\text { 2009:81). }\end{array}$ & 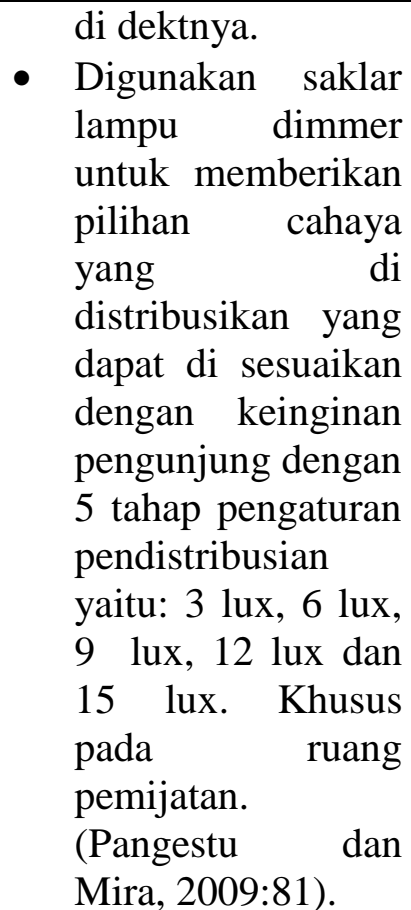 & & \\
\hline
\end{tabular}

Tabel 3. Ringkasan fungsi kebutuhan pencahayaan terkait fungsi ruang reflexology.

\section{KESIMPULAN}

Tahap analisis dilakukan untuk mengetahui kajian sistem pencahayaan buatan mampu membantu proses relaksasi pengguna terhadap ruang reflexiology di Everyday Balinese Spa and Reflexiology.

Dari hasil analisa yang telah diakukan, dapat disimpukan sebagai berikut:

1. Bahwa pencahayaan buatan pada ruang reflexology di Everyday Balinese Spa \& Reflexology sudah cukup sesuai dengan fungsi kenyamanan visual terkait relaksasi tubuh karna pada ruang reflexology menggunakan 2 lampu fluorescent 50-60 watt Temperatur warna 3000k, CRI 80+. Luminair: downlight yang tersembunyi di plafon dengan dilapisi trim lensa di lorong ruangan, sehingga fungsi pencahayaan disana hanya difungsikan sebagai media bantu treatment untuk mendapatkan proses relaks dengan pencahayaan yang redup bila berada dalam ruang yang dilapisi tirai. Yang sesuai dengan yang dikatakan Flynn dalam buku Interior Lighting For Designer oleh Gary Gordon (2003:46) bahwa warna hangat (3000K) menunjukan impresi kenyamanan, terutama disaat perasaan rileks sangat dibutuhkan.

2. Terdapat berbagai macam jenis pencahayaan yang ada, yang semuanya tergantung dari aspek-aspek seperti jenis pencahayaanya, teknik penerangannya, warna yang dikeluarkan, dan beberapa hal lainya yang seluruhnya turut berperan serta dalam menentukan efek pada ruang dan para penggunanya. 
3. Selain dari jenis pencahayaan dan teknik penerangan, warna dari lampu juga turut menciptakan beberapa jenis atmosfer pada ruang, dimana cahaya tertentu menimbulkan efek yang tergantung pada tiap individu yang melihatnya.

4. Sebagai tempat yang menjanjikan fasilitas relaksatif bagi para penggunanya, aspek interior dalam pusat perawatan tubuh dan kecantikan pun turut mendukung tujuan akhir tersebut dengan caranya sendiri, sebagaimana cahaya mempengaruhi sebuah kesan di dalam ruang yang juga dapat membawa kesan releksatif bagi tiap individu.

\section{DAFTAR PUSTAKA}

[1] Dewi pangestu, Mira, (2009), Pengaruh kenyamanan psiko-visual dari pencahayaan buatan, Arsitektur, vol 3, hal 81.

[2] Gallery Everyday Spa, Available at: http://www.everydayspa.co.id/\#gallery Accessed: 2015-11-3.

[3] George C. Brainard, Available at: http://www.controlledenvironments.org/Light1994Conf/index.htm Accessed: 2015$10-28$

[4] Kim, stevwri. Effect of interior structure and lights on human mood changes and social behavior. Available at: https://kimstevewri101.wordpress.com/literaturereview/effects-of-interior-structure-and-lights-on-human-mood-changes-and-socialbehavior/ Accessed: 2015-10-28

[5] Lechner, Norbert. Lighting chapter 12, pada buku Heating, Cooling, Lighting, Sustainable Methods For Architects, PT.Rajagrafindo Persada, Jakarta, (2007)

[6] Rees. tipe penerangan ruang chapter 9, pada buku Lighting Styles. Octopus Publishing Group Limited. London (1999)

[7] S.H. Wan, J. Ham, D. Lakens, J. Weda, dan R. Cuppen2, The Influence of Lighting Color and Dynamics on Atmosphere Perception and Relaxation Available at : http://www.experiencinglight.nl/ Accessed: 2015-10-28 